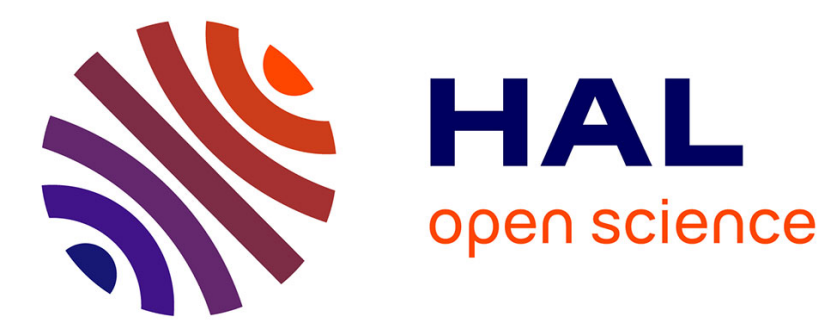

\title{
Drivers' visual attention: A field study at intersections
}

\author{
Sophie Lemonnier, Lara Désiré, Roland Bremond, Thierry Baccino
}

\section{To cite this version:}

Sophie Lemonnier, Lara Désiré, Roland Bremond, Thierry Baccino. Drivers' visual attention: A field study at intersections. Transportation Research Part F: Traffic Psychology and Behaviour, 2020, 69, pp 206-221. 10.1016/j.trf.2020.01.012 . hal-02466983v2

\section{HAL Id: hal-02466983 \\ https://hal.science/hal-02466983v2}

Submitted on 31 May 2021

HAL is a multi-disciplinary open access archive for the deposit and dissemination of scientific research documents, whether they are published or not. The documents may come from teaching and research institutions in France or abroad, or from public or private research centers.
L'archive ouverte pluridisciplinaire HAL, est destinée au dépôt et à la diffusion de documents scientifiques de niveau recherche, publiés ou non, émanant des établissements d'enseignement et de recherche français ou étrangers, des laboratoires publics ou privés. 


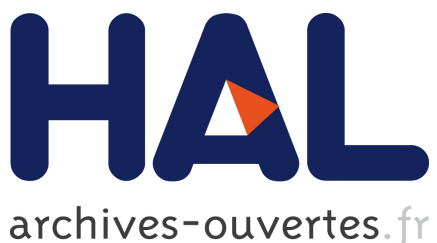

archives-ouvertes

\title{
Drivers' visual attention: A field study at intersections
}

\author{
Sophie Lemonnier, Lara Désiré, Roland Brémond, Thierry Baccino
}

\section{To cite this version:}

Sophie Lemonnier, Lara Désiré, Roland Brémond, Thierry Baccino. Drivers' visual attention: A field study at intersections. Transportation Research Part F: Traffic Psychology and Behaviour, Elsevier, 2020, 69, pp.206-221. 10.1016/j.trf.2020.01.012 . hal-02466983

\section{HAL Id: hal-02466983 \\ https://hal.archives-ouvertes.fr/hal-02466983}

Submitted on 21 Dec 2020

HAL is a multi-disciplinary open access archive for the deposit and dissemination of scientific research documents, whether they are published or not. The documents may come from teaching and research institutions in France or abroad, or from public or private research centers.
L'archive ouverte pluridisciplinaire HAL, est destinée au dépôt et à la diffusion de documents scientifiques de niveau recherche, publiés ou non, émanant des établissements d'enseignement et de recherche français ou étrangers, des laboratoires publics ou privés. 


\title{
Drivers' visual attention: a field study at intersections.
}

\author{
Sophie Lemonnier ${ }^{\mathrm{a}}$, Lara Désiré ${ }^{\mathrm{b}}$, Roland Brémond $^{\mathrm{c}, *}$, Thierry Baccino ${ }^{\mathrm{d}}$ \\ ${ }^{a}$ Université de Lorraine, PErSEUs, F-57000 Metz, France \\ ${ }^{b}$ Centre d'Etudes et d'expertise sur les Risques, l'Environnement, la Mobilité et \\ l'Aménagement (CEREMA), Project-team STI, 5 rue Jules Vallès, F-22015, Saint-Brieuc, \\ France \\ ${ }^{c}$ Laboratoire Exploitation, Perception, Simulateurs et Simulations (LEPSiS), Institut \\ Français des Sciences et Technologies des Transports, de l'Aménagement et des Réseaux \\ (IFSTTAR) \\ ${ }^{d}$ Université de Paris VIII, Laboratoire Cognitions Humaine et Artificielle (CHArt-LUTIN)
}

\begin{abstract}
Crossing a road intersection, a driver must collect a certain amount of visual information from various locations. The allocation of visual attention, which allows this collection, mainly relies on top-down processes. This study focuses on three top-down factors which influence the collection of visual information: the value of visual information for the ongoing task, their bandwidth, and the familiarity with the environment. These factors are studied according to the priority rules at intersections (Give way, Stop or Priority), the expected traffic density (Lower or Higher) and the number of passages (First or Second passage). Fourteen participants were installed in an instrumented vehicle equipped with an eye-tracker. They drove during $1 \mathrm{~h} 45$ along a $80-\mathrm{km}$ long route, mainly on rural roads, which included 19 intersections. Visual attention was studied by means of the head and gaze horizontal eccentricity. Effects were found for each of the three factors, in agreement with Wickens' theoretical framework and with previous studies, despite the important variability in the data due to the experimental situation.
\end{abstract}

Keywords: Top-down visual attention, Road intersection, Eye tracking

\footnotetext{
*Corresponding author

Email address: roland.bremond@ifsttar.fr (Roland Brémond)
} 


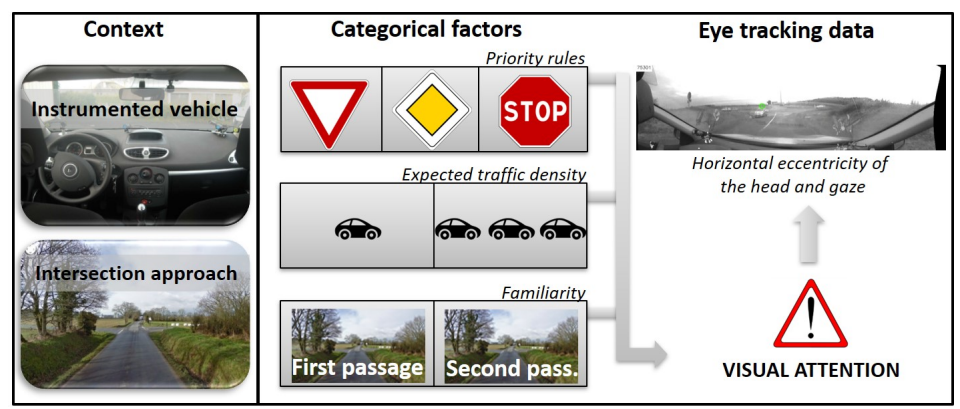

\section{Introduction}

Anticipation is paramount when driving in a complex environment. A large part of the effort of understanding what is going on around us is allocated to predictions about the state of the environment in the near future (Endsley,

5 1995, Montel et al. 2004, Engström et al. 2018). This is particularly true with regard to the road environment, where it is possible to make predictions with reasonable chances of success. In particular, the road traffic regulations define formal rules: the road is an artificial environment designed to make anticipation easier and to facilitate the collection of visual information. It is composed of elements of the road landscape (e.g. crosswalks, intersections, road markings) together with contextual and variable elements (e.g., road traffic, weather, time of the day) (Solt, 2017). Sometimes, semantic information is explicitly delivered (e.g., traffic lights, road signs, road markings).

Visual attention is the first step of information collection during the driving task, selecting relevant items in the field of view and allowing them to appear in central vision, where the human visual system provides better perception of details and colors.

The number of accidents at intersections each year makes this situation particularly important. In 2017 in France, 18,507 accidents with personal injuries occurred at intersections (608 deaths and 7,559 hospitalizations), which corresponds to $18 \%$ of road deaths and $27 \%$ of hospitalizations (ONISR, 2017). It 
should be noted that $17 \%$ of the accidents at intersections occur outside urban areas, while they cause $53 \%$ of the deaths.

Approaching an intersection requires a specific behavior involving the detec25 tion and anticipation of a possible collision. The driver needs to collect visual information on all branches of the intersection, together with the information needed for vehicle control. Specific visual information is required to anticipate the behavior of the other vehicles, and to decide whether to stop or not. All in all, this includes most of the driver's visual field, while the focus of attention can be directed to only one location at a time.

According to the three cognitive levels of driving described in most models of the driving task (Allen et al., 1971; Michon, 1985), the decision-making subtask associated to intersection crossing belongs to the tactical level (maneuvering): it needs a short-term decision (in seconds), and needs visual information about

35 the road environment and the vehicles around. Simultaneously, during the intersection approach, the vehicle control subtasks (at the operational level of the hierarchy), that is, the control of the heading and of the lateral and longitudinal position, are still needed and require specific visual information.

Relevant information for the intersection crossing decision subtask is located 40 where the danger comes from: on the lanes that the driver is about to cross (see the "lateral branches" yellow boxes on Figure 11. For the sensorimotor subtasks of vehicle control, most of the information is taken in central vision $\bigsqcup^{1}$ from the driver's own roadway: the lane edges, the vanishing point, the tangent point, a vehicle in front, the far and near points, or even the road texture, depending

45 on the traffic and the road geometry (Donges, 1978, Land \& Horwood, 1995. Chatziastros et al., 1999; Salvucci \& Gray, 2004, Lappi, 2014, Lappi \& Mole, 2018) (see the "driver's road" yellow boxes on Figure 1).

Before reaching an intersection, the driver needs to collect information about the traffic on the lateral branches. Therefore, the main source of visual informaso tion for the decision-making task comes from those areas. But some trade-off is

\footnotetext{
${ }^{1}$ The optic flow also gives important visual cues (Mole et al. 2016.
} 


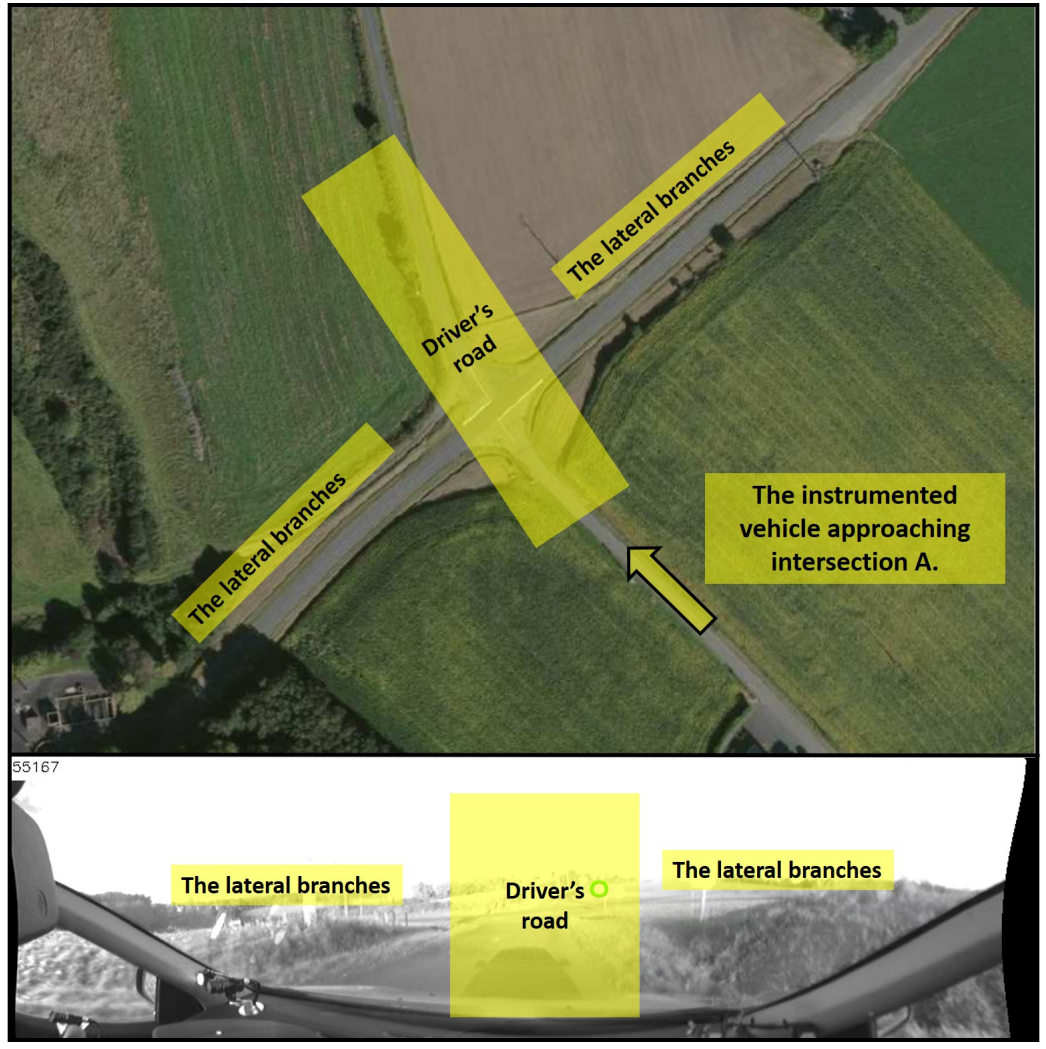

Figure 1: Top: bird's view of a stop intersection (intersection A in Table 1). The image is extracted from www.geoportail.gouv.fr. Bottom: view of the same intersection from the onboard camera. The "lateral branches" yellow boxes refer to the areas where visual information can be collected for the decision-making subtask, while information for the vehicle control subtask is taken from the "driver's road" yellow box.

needed between collecting visual information for the intersection crossing subtask and for vehicle control. Information collection (and gaze allocation) in the lateral branches and on the driver's road should therefore vary according to what each new piece of information will bring to the driver, resulting in alter55 nate gaze allocation. Let's see what factors may modulate the gain associated with each type of visual information.

Top-down factors. When the allocation of visual attention is task-driven, it is called top-down attention, and depends on the current goals. On the opposite, 
bottom-up allocation of visual attention (data-driven) depends on the characteristics of the visual scene (Koch \& Ullman, 1985, Wolfe \& Horowitz, 2004). The present research focuses on the factors that influence top-down attention, especially since top-down processes seem to be more influential, compared to bottom-up processes, when the task is particularly complex (Foulsham et al. 2011, Land \& Tatler, 2009) as well as in natural settings (Hayhoe \& Ballard, 65 2005 Land \& Furneaux, 1997, Trick et al., 2004, Land, 2004; Tatler et al., 2011).

According to Senders (1966), top-down visual attention is driven by two factors: the expectancy and the value of the information. The value refers to the relevance of an element of information for a given task. In the case of the intersection approach, the lateral branches provide the relevant information to make the decision, namely the speed, distance and behavior of the approaching vehicles. However, the relevance of this information depends on the priority rule (Priority, Stop or Give way), which modulates the value of this information.

In the sense of Senders (1966), the expectancy associated to a given area of interest is the quantity of information in this area relevant for the task at hand.

75 He also introduced in this context the notion of information flow, the bandwidth, which corresponds to the frequency of information renewal. It is considered as modulating the expectancy associated to a given source of information, and as such it is expected to impact the allocation of visual attention towards this source.

so Senders theoretical model was consolidated in the literature by experimental studies to test its predictions through the visual occlusion protocol, which provides a dynamic approach to the visual requirements of driving (Senders et al. 1967, Kujala et al., 2016).

Wickens et al. (2001, 2003) have proposed a model for the allocation of visual ${ }_{85}$ attention based on Senders theoretical model. If some relevant information in a given area change over time, the bandwidth associated to this area will be more important, because the information already collected quickly become obsolete. During the approach of the intersection, one may speculate that the expected traffic density in the lateral branches modulates the bandwidth, that is, the 
speed at which previous information becomes useless.

The information already in memory may also tune the allocation of attention in a top-down way (Awh et al. 2012). Studies from Mourant \& Rockwell (1970) and Martens \& Fox (2007) on familiarity showed that after three drives on the same route, the amount of visual search and the number of gaze on road

95 signs decreases. Indeed, information available in memory influences how the driving task is performed (Shinoda et al. 2001, Lappi et al. 2017), and previous knowledge associated with the task may affect the allocation of visual attention (Logan, 2002). This explains why visual exploration may differ depending on the number of times the task has already been completed. In other words, a learning effect is expected. In our study, familiarity was considered, comparing the first and second crossing at some of the intersections.

The aim of this paper is to test the impact of these three factors - the priority rule, the expected traffic density and the familiarity — on the allocation of visual attention in a real driving situation. For that purpose, we propose predictions for each of these factors, detailed below; they will be compared to observations in the field.

Predictions concerning the priority rule. This study considered three priority rules at intersections: Stop, Give-way and Priority. These rules require specific behaviors, and therefore should influence the driver's decision to stop or not.

In the Stop condition, the decision to stop is mandatory. Therefore, the value of the information from the lateral branches should be close to zero when approaching an intersection with a Stop sign.

In the Priority condition, the decision not to stop is strongly suggested. However, the associated behavior implies some potential interactions with the

115 other road users. Indeed, even through other drivers ought to give way, a collision is possible, and the driver can decide to stop if he perceives such a risk. For these reasons, the value of the information from the lateral branches should be higher than in the Stop condition.

In the Give-way condition, the decision is not imposed; it strongly depends 
the lateral branches are more useful in this condition than in the two others, so their value is expected to be the highest.

Considering that the more relevant an information is, the more it is looked at, our hypothesis is that the visual exploration of the environment is more Priority condition than in the Stop condition.

Predictions concerning the expected traffic density. In the Give-way condition, the task difficulty depends on the traffic, as the drivers continuously need to check for a possible collision. But how does the task difficulty changes with the traffic density? This is not straightforward. In previous studies, heavy traffic has been associated with a more difficult driving task, but the specific driving task was often different from the present scenario. For example, Werneke \& Vollrath (2012) showed that when the driver stops at a T-junction with the intention of turning right, more gaze allocation is observed on the left lane with 135 increasing traffic density. This suggests that visual exploration increases with traffic density. But in their study, the task was to decide when to restart, not whether to stop or not.

In a study similar to the one presented in this paper, but in a driving simulator, visual exploration was studied in relation to the driving subtasks (Lemonnier 140 cided whether to stop or not, showing a completely different exploration profile for the decision to stop compared to the decision to restart. In our case, at least with a Stop or a Give Way sign, it can be speculated that the task difficulty would decrease with increasing traffic density, as the decision to stop becomes easier. Thus, our hypothesis with Stop and Give Way is that visual exploration on the lateral branches decreases with increasing traffic density.

Predictions about the familiarity. In a driving simulator study, Martens (2004) asked participants to cross the same intersection several times. With training, 
she observed a decrease of the total dwell time in certain areas of interest associated with the task. She reproduced her study in real settings (Martens \& Fox 2007), and similarly observed a decrease of the total fixation times and of the total number of fixations in areas of interest related to the task over the course of the trials (one circuit per day over three days). These results are consistent with the idea that when the environment becomes familiar, the relevance (value) of visual information from the lateral branches decreases, and so does the visual exploration.

In our study, the participants had to cross some of the Give-way intersections twice. Our hypothesis with respect to route familiarity is that the visual exploration decreases between the first and the second passing of these intersections.

\section{Material and method}

\subsection{Participants}

Fourteen participants (11 men, 3 women) took part in the experiment. They were recruited within the Cerema and the DDTM (this includes various departments of the ministry of Transport, Public Works and Environment, SaintBrieuc, France). All participants had a normal or corrected-to-normal vision, and had their driving license for at least six years. On average, these participants were 44 years old $(S D=11)$, had their driving license for 25 years $(S D=$ $13)$, and estimated they drove $311 \mathrm{~km}$ per week $(\mathrm{SD}=229)$.

\subsection{The instrumented vehicle}

The vehicle was a Renault Clio III with a manual transmission instrumented by Cerema.

\subsubsection{The eye-tracker}

The eye-tracker was a Smart Eye Pro 5.9. It was fixed inside the vehicle and had a sampling frequency of $60 \mathrm{~Hz}$. It used four monochromatic cameras 
(XC HR50; Sony) fixed on the dashboard to record the driver's face from four different angles (see Figure 2 A).

The eye-tracker allowed collecting the head and gaze directions with respect to the vehicle axis (which was fixed in the eye-tracker system configuration). For each participant, a head model is computed, then the gaze direction can be calculated. These settings allowed the collection of head angles (horizontal, vertical and roll) and gaze angles (vertical and horizontal). Two infra-red light sources pointed at the driver, allowing the cameras to detect corneal reflection (see Figure 2, B). Three cameras were fixed under the rear-view mirror (see Figure 2, C) to capture the environment in front of the vehicle. The eye tracking system was managed by a computer placed in the trunk of the vehicle (SSTSG01-B; SilverStone Technology) equipped with two video capture cards, Smart Eye Pro 5.9 software, and SceneRecorder software.

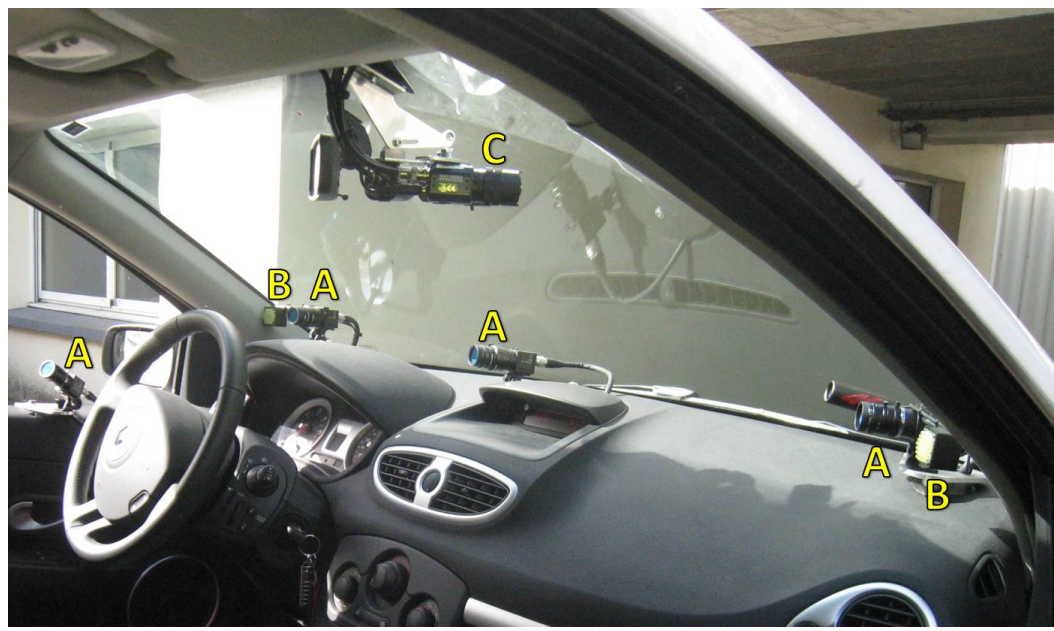

Figure 2: Photograph of the instrumented vehicle. A: Cameras to collect gaze information. B: Infra-red lamps. C: Scene cameras.

\subsubsection{Vehicle data}

Speed and position of the vehicle were recorded with a dedicated computer (DIRCO, developed by the LIVIC-IFSTTAR and Lolitech company), connected to the Controller Area Network (CAN) bus and a GPS receiver. GPS data 
were used to select the data along the road sections and intersections under investigation. These data were collected at a sampling rate of $25 \mathrm{~Hz}$.

\subsubsection{Synchronization}

A third computer, equipped with The Observer XT software (Noldus Information Technology) managed the system, launching the eye tracking software (SceneRecorder and Smart Eye Pro 5.9; SmartEye), the video acquisition from indoor cameras and microphone (MediaRecorder; Noldus Information Technology) and sending a synchronization signal to the DIRCO computer. This configuration allowed automatic synchronization of the CAN bus and GPS data with the videos. The eye-tracker data were synchronized with the above data thanks to The Observer XT software.

\subsection{The route and the intersections}

The route was about $80 \mathrm{~km}$ long near the city of Saint-Brieuc, France (see Figure 3). It provided mostly single carriageway road sections in rural environments but also included dual carriageway sections and single carriageway sections in urban areas.

On this route, eight intersections composed of two roads intersecting at $90^{\circ}$ were selected for analyses. These intersections were chosen in order to sample the three types of priority rules (Stop, Give way and Priority). They were all interurban, except one in an open urban area (intersection $\mathrm{H}$ ).

The same intersection could be crossed several times, either from another direction, or in the same direction but later in the experiment. It was these 215 crossings, not the intersections, that formed the trials of our experimentation. Given that we were interested in the approach of the intersections (the last 100 meters) and not in their crossing, a trial corresponded to an approach. There were 19 trials, each one being described based on its priority rule, the expected traffic density at this intersection and the Passage order (see Table 1). 


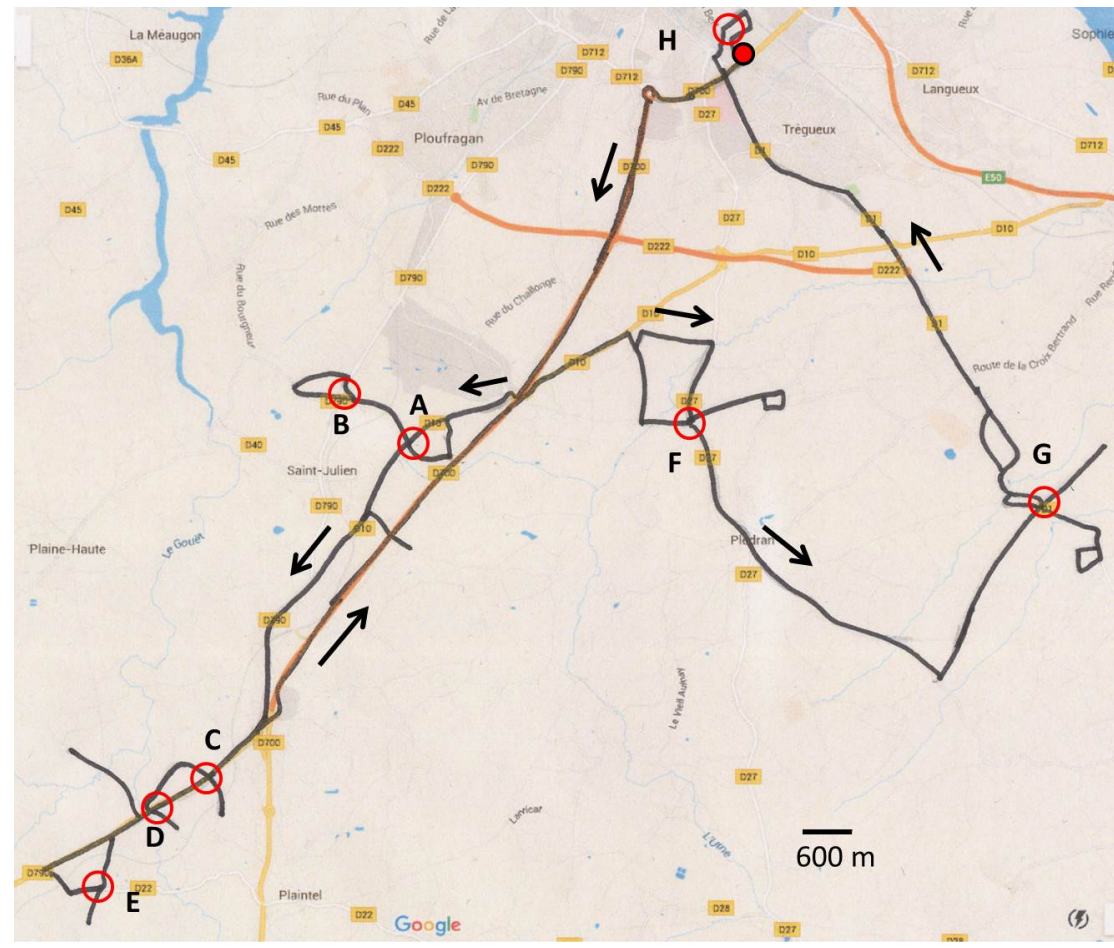

Figure 3: Top view of the route. The red circles indicate the intersections. Their label from A to $\mathrm{H}$ corresponds to those presented in Table 1 The GPS coordinates of these intersections are A: $48^{\circ} 27^{\prime} 22.2^{\prime \prime} \mathrm{N} 2^{\circ} 48^{\prime} 04.4^{\prime \prime} \mathrm{W}$; B: $48^{\circ} 27^{\prime} 38.2^{\prime \prime} \mathrm{N} 2^{\circ} 48^{\prime} 44.2^{\prime \prime} \mathrm{W}$; C: $48^{\circ} 25^{\prime} 14.6^{\prime \prime} \mathrm{N} 2^{\circ} 49^{\prime} 55.5^{\prime \prime} \mathrm{W}$; D: $48^{\circ} 25^{\prime} 01.8^{\prime \prime} \mathrm{N} 2^{\circ} 50^{\prime} 29.4^{\prime \prime W}$; E: $48^{\circ} 24^{\prime} 31.0^{\prime \prime} \mathrm{N} 2^{\circ} 50^{\prime} 59.1^{\prime \prime} \mathrm{W} ; \mathrm{F}: 48^{\circ} 27^{\prime} 30.9^{\prime \prime} \mathrm{N} 2^{\circ} 45^{\prime} 20.8^{\prime \prime} \mathrm{W} ; \mathrm{G}$ : $48^{\circ} 27^{\prime} 00.1^{\prime \prime} \mathrm{N} 2^{\circ} 42^{\prime} 00.3^{\prime \prime} \mathrm{W}$; H: $48^{\circ} 30^{\prime} 00.8^{\prime \prime} \mathrm{N} 2^{\circ} 45^{\prime} 04.2^{\prime \prime} \mathrm{W}$. The red (resp. black) dot indicates the start (end) of the route; the arrows give a general idea of the direction of the circuit. Map taken from Google Maps.

\subsection{Procedure}

The experimenter first explained to the participant the general course of the experiment. The participant was then asked to complete an informed consent form. He entered the instrumented vehicle and was asked to sit comfortably, with the option of adjusting the seat and mirrors. To become familiar with the vehicle, he was asked to drive in the presence of the experimenter on a 5 -minute tour. Then, he completed a general purpose questionnaire, while a second experimenter prepared the vehicle. 


\begin{tabular}{|l|l|l|l|l|}
\hline Trials & Intersections & Priority rule & Expected traffic & Passage \\
\hline 1 & A & Stop & Lower & $/$ \\
2 & B & Give way & Lower & First \\
3 & B & Give way & Lower & Second \\
4 & A & Stop & Lower & $/$ \\
5 & A & Priority & $/$ & $/$ \\
6 & C & Priority & $/$ & $/$ \\
7 & C & Give way & Higher & First \\
8 & C & Give way & Higher & Second \\
9 & D & Give way & Higher & $/$ \\
10 & E & Stop & Lower & $/$ \\
11 & D & Priority & $/$ & $/$ \\
12 & C & Priority & $/$ & $/$ \\
13 & F & Stop & Higher & $/$ \\
14 & F & Priority & / & First \\
15 & G & Give way & Lower & Second \\
16 & G & Give way & Lower & $/$ \\
17 & G & Priority & $/$ & $/$ \\
18 & G & Priority & $/$ & Higher \\
19 & H & Stop & \\
\hline
\end{tabular}

Table 1: The chronological order of the trials (intersection approach) is given in the first column. Column 2 gives the intersections label from Figure 3 The priority rule, the expected traffic density and (when needed) the crossing order is given in the last column.

The calibration of the eye-tracker was done with the second experimenter. The positions of the four cameras on the dashboard were adjusted to the participant. A head model was then calculated by the software, then the gaze calibration was made using five points, four on the car hood and one on the windshield. This calibration was checked with various control points inside and outside the vehicle (the latter were more than 10 meters away in front of the vehicle).

235 The participant was told to drive as if he was alone in the car, even though the first experimenter sat in the right rear seat. A GPS navigator was used to give auditory information about the directions to follow. In case of doubt, it was suggested that it would be better to make a decision without asking the experimenter. The GPS navigator was behind the passenger's seat, so that it 240 could not be seen by the participant. Only auditory information was available 
to him, in order to avoid an additional source of visual information. Then, the participant started to drive. The experiment lasted on average $3 \mathrm{~h}$, including 1h45 driving (never more than $2 \mathrm{~h}$ ).

\subsection{Independent variables}

245 Road sections. To account for behavioral changes during an intersection approach, a road section factor was also defined. The last 100 meters before the intersection were divided into three sections: from 100 to 66 meters, from 66 to 33 meters, and from 33 to 0 meters before the intersection.

Priority rule. The first independent variable was the priority rule, with the following conditions: Give way, Stop and Priority.

Expected traffic density. In the Stop and Give Way conditions, the expected traffic density was defined at each intersection as an a posteriori factor.

In a previous study (Lemonnier et al. 2015), the bandwidth of visual information was modulated by controlling the actual traffic density on the intersect255 ing road. The authors suggested that it is not the actual traffic that modulates the allocation of visual attention, but the expected traffic. Indeed, the environment gives implicit information that the driver gets from visual cues, such as the road width, roadside environment and the like, which contribute to suggest the level of traffic at any given intersection.

As a rough estimate of the traffic density, the onboard experimenter noted the number of vehicles crossing the intersection from the lateral branches during each approach. From these data, the average traffic across participants was computed for each intersection. Two categories of traffic density have been constructed from these data, Lower and Higher.

265 The observed mean traffic density (across participant) was labelled as Lower or Higher, depending on a specific threshold. This threshold was different for Give Way and Stop intersections, because we wanted to have nearly the same number of intersections in each of the two traffic classes, both at Give way and Stop intersections. In the Priority condition, the number of vehicles on the 

of the two priority conditions, and are therefore different. The analyses with respect to this factor were restricted to Give way and Stop intersections.

Familiarity. A third factor was built to account for the driver's familiarity with the environment. It was only relevant at the three Give-way intersections that

285 the participants crossed twice, so that the analyses were restricted to a subset of the data. This factor has two conditions, First and Second passage, and concerns three zones (see Table 1).

\subsection{Dependent variables}

The visual exploration is studied through the horizontal eccentricity of the head and gaze angles of the driver. Horizontal eccentricity is defined as the absolute value of the horizontal component of the gaze (and head) direction angle; a zero value corresponds to the vehicle roll axis. We used mean absolute value because we had no hypothesis regarding the right/left symmetry of gaze. This was allowed on the one hand by the research question, related to the 295 search for information in relation to the vehicle control and intersection crossing subtasks; and on the other hand by the symmetry of the chosen intersections.

An increase in horizontal eccentricity will be interpreted as an increase in visual exploration, increasing the amount of relevant visual information collected from the intersecting road. 
The analyzed data are those collected during the last 100 meters before crossing each intersection. The choice of this distance was determined by the constraints of the field situation. Indeed, the intersections were selected so that the road section before each intersection was as similar as possible across intersections in terms of visibility and trajectory. Given the topography of the road network, it was decided to focus on the last 100 meters. The end of a trial was either when the participant arrived at the intersection entrance, or when the vehicule speed dropped below $1 \mathrm{~m} / \mathrm{sec}(3.6 \mathrm{~km} / \mathrm{h})$. This allowed focusing on the data related to the approach, not on the stop and the restart.

The first part of the Results section is devoted to descriptive analyses of the vehicle data: number of stop behaviors and average speed per condition. Then, the gaze and head horizontal eccentricity are analyzed. Two series of $3 \times 3$ within-subject repeated measures ANOVAs, for the head and for the gaze, were conducted to study the priority rule (Give way, Stop and Priority) and the 315 position ahead of the intersection (the three road sections). Additional $2 \times 2 \times 3$ within-subject repeated measures ANOVAs were conducted in order to study the expected traffic density (Lower and Higher), the priority rule (Give way and Stop) and the position (the three road sections). Finally, $2 \times 3$ within-subject repeated measures ANOVAs were conducted to study the familiarity (First and 320 Second passage) and the position (the three road sections).

The gaze and head horizontal eccentricities were normally distributed. The significance threshold was set to .05, but in order to be consistent with Johnson (2013) and Benjamin et al. (2018), the values of $p$ are given when $p>.001$. In each of the upcoming figures presenting the observed results, the error bars 325 represent the Standard Error of the Mean (SEM). 


\section{Results}

\subsection{Stop behavior and speed}

All participants systematically stopped at intersection with either a Stop or a Give-way, and conversely, they all passed without stopping with a Priority.

did not observe any non-stop behavior with the Stop and Give-Way priority rule conditions, which can be explained by the presence of the experimenter.

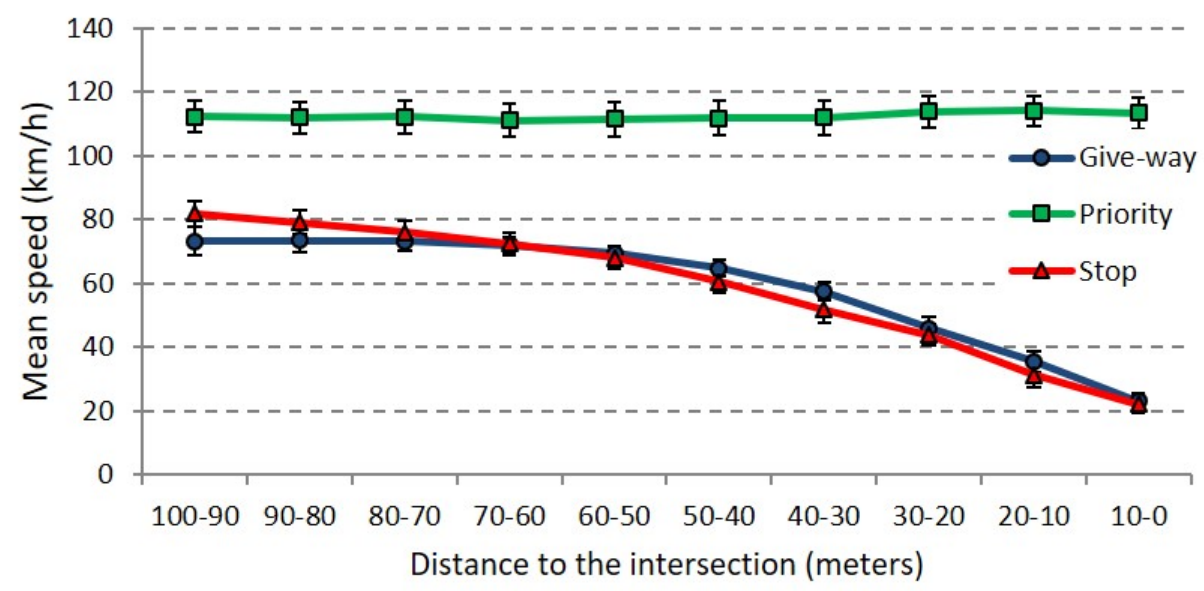

Figure 4: Average speed during the intersection approach for each of the three priority rules (Give way, Stop and Priority).

The average speed of the participants are shown in Figure 4. The speed is rather constant with a Priority sign during the 100 meters of the approach, whereas it decreases in the Stop and Give-way conditions, which is consistent with the systematic stopping behaviors in these two conditions. The patterns are very similar to those observed in a previous study in a driving simulator (Lemonnier et al. 2014).

\subsection{The priority rule and the road section}

Individual data of the gaze eccentricity is plotted in Figure 5 for three intersections, with each of the three priority rules. It gives some intuitive sense of the data. 


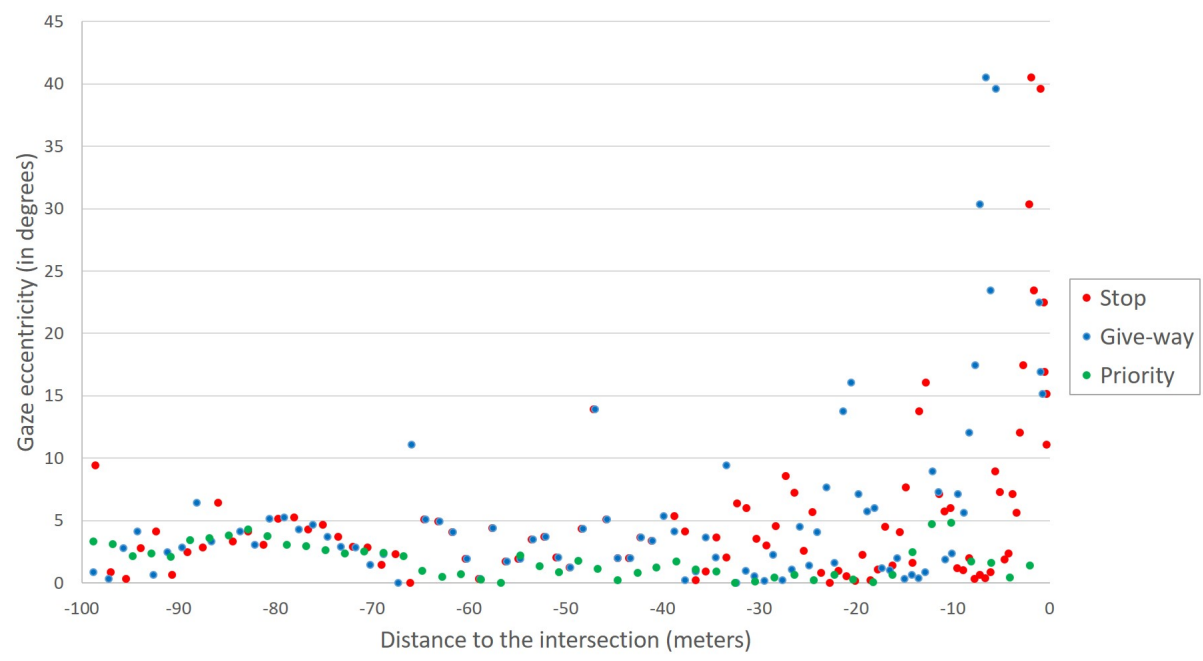

Figure 5: Horizontal eccentricity of the first participant's gaze during the approach of three intersections (Stop at intersection A, trial 1; Give way at intersection B, trial 2; Priority at intersection A again, trial 5; see Table 1 .

In order to study the effects of the priority rule (Priority, Give-way, Stop) and of the position with respect to the intersection (the three road sections), $3 \times 3$ repeated measures ANOVAs were conducted on the gaze and head horizontal eccentricities. The average values and standard deviations obtained in each condition are presented in Table 2 ,

\begin{tabular}{crrr} 
Priority rule & Section & Head & Gaze \\
\hline \multirow{3}{*}{ Give way } & $100-66 \mathrm{~m}$ & $5.08(1.48)$ & $6.87(1.33)$ \\
& $66-33 \mathrm{~m}$ & $5.44(2.57)$ & $8.26(2.08)$ \\
& $33-0 \mathrm{~m}$ & $11.77(3.00)$ & $9.80(2.16)$ \\
\hline \multirow{3}{*}{ Priority } & $100-66 \mathrm{~m}$ & $4.09(1.89)$ & $5.33(1.85)$ \\
& $66-33 \mathrm{~m}$ & $4.09(1.58)$ & $5.63(1.36)$ \\
& $33-0 \mathrm{~m}$ & $5.59(2.63)$ & $6.18(2.10)$ \\
\hline \multirow{3}{*}{ Stop } & $100-66 \mathrm{~m}$ & $4.45(1.68)$ & $6.16(1.85)$ \\
& $66-33 \mathrm{~m}$ & $5.25(2.08)$ & $7.44(1.61)$ \\
& $33-0 \mathrm{~m}$ & $11.83(3.93)$ & $9.36(2.92)$
\end{tabular}

Table 2: Mean and standard deviation values (in degrees), for the head and gaze horizontal eccentricity, according to the priority rule and the road section.

For each of these analyses, when a significant effect was found, the contrasts 
between each condition of the priority rule for each road section, as well as between each road section for each of the priority rule conditions, were tested.

350 Given the large number of contrasts, a post-hoc multiple comparisons test was more suitable than a planned comparison and a Tukey HSD test (Honestly Significant Difference) was therefore conducted.

Gaze eccentricity. Significant effects of the priority rule and of the road section were found: the priority rule, $F(2,26)=25.32, M S E=3.03, p<.001, \eta^{2}=$ $355 \quad 0.661$; the road section, $F(2,26)=14.70, M S E=3.90, p<.001, \eta^{2}=0.531$. A significant interaction was also found, $F(4,52)=3.25, M S E=1.80, p=0.019$, $\eta^{2}=0.200$

For the 100-66 meters road section, there was no difference between the three priority rule conditions (Give-way vs. Stop: $p=0.082$; Give-way vs. Priority: $360 p=0.892$; Priority vs. Stop: $p=0.782$ ). For the $66-33$ meters and $33-0$ meters sections, the gaze horizontal eccentricity was smaller in the Priority condition than in the Give-way (66-33 m: $p<.001 ; 33-0$ m: $p<.001)$ and Stop (66-33 $\mathrm{m}: p=0.020 ; 33-0 \mathrm{~m}: p<.001)$ conditions, without any significant difference between these last two conditions (66-33 m: $p=0.798 ; 33-0 \mathrm{~m}: p=0.994)$, see

365 Figure 6 .

In the Give-way condition, the gaze horizontal eccentricity increased between the 100-66 and 33-0 meters road sections $(p<.001)$, without any difference between the 100-66 and 66-33 road sections ( $p=0.156)$, or between the $66-33$ and $33-0$ sections $(p=0.084)$. In the Stop condition, the horizontal eccentricity did not change significantly between the 100-66 and 66-33 meters sections ( $p=$ $0.241)$, but increased between the $66-33$ and $33-0$ sections $(p=0.011)$. In the Priority condition, the gaze horizontal eccentricity did not change significantly between the 100-66 and 66-33 sections ( $p=1$ ), or between the 66-33 and 33-0 sections $(p=0.974)$.

375 Head eccentricity. Significant effects of the priority rule and of the road section were found on the head horizontal eccentricity: the priority rule, $F(2,26)=$ 21.53, $M S E=4.81, p<.001, \eta^{2}=0.624$; the road section, $F(2,26)=48.14$, 

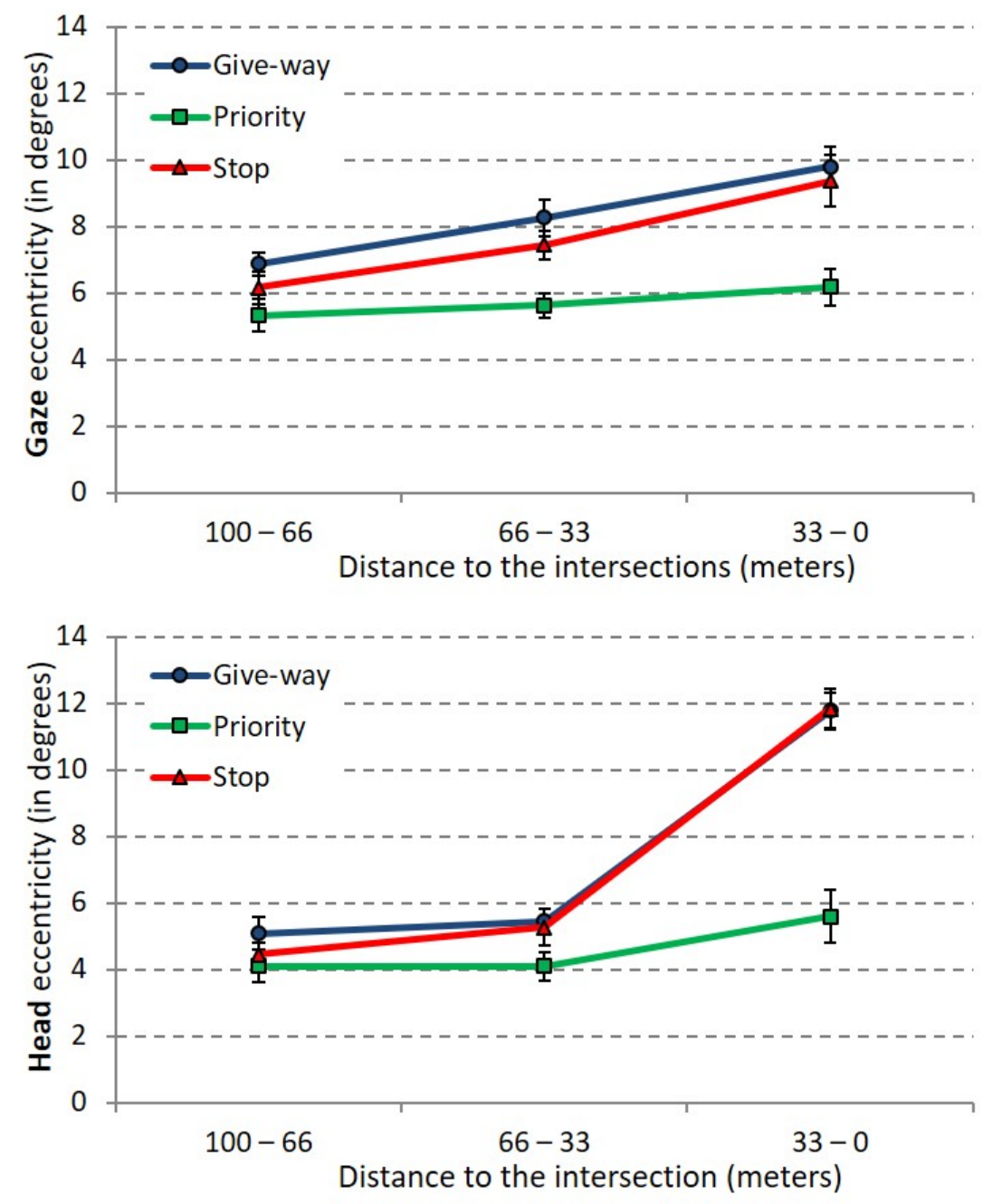

Figure 6: The absolute value of gaze and head horizontal eccentricity angles (in degrees) according to the road section ahead of the intersection and the priority rule.

$M S E=7.29, p<.001, \eta^{2}=0.787$. A significant interaction was also observed, $F(4,52)=10.06, M S E=4.34, p<.001, \eta^{2}=0.436$ (see Figure 6).

In the 100-66 and 66-33 meters road sections, there was no significant difference between the different priority rule conditions (Give-way vs. Stop, 100-66 $\mathrm{m}: p=0.996,66-33 \mathrm{~m}: p=1$; Give-way vs. Priority, 100-66 m: $p=0.940$, 
66-33 m: $p=0.737$; Priority vs. Stop, 100-66 m: $p=1$; 66-33 m: $p=0.866$ ).

In the 33-0 meters road section, the head eccentricity was smaller in the Priority than in the Give-way $(p<.001)$ and Stop conditions $(p<.001)$, without any significant difference between these last two $(p=1)$.

The head horizontal eccentricity did not change significantly between the 100-66 and 66-33 meters road sections for any of the three priority rule conditions (Give-way: $p=1$; Priority: $p=1$; Stop: $p=0.982$ ). However, it increased between the 66-33 and 33-0 meters sections in the Give-way $(p<.001)$ and Stop $(p<.001)$ conditions, not in the Priority condition $(p=0.619)$.

\subsection{Expected traffic density}

The modalities of the expected traffic density factor were built a posteriori, and only on Give-way and Stop intersections.

Two $2 \times 3 \times 2$ repeated measures ANOVAs were conducted on the gaze and head horizontal eccentricity. The factors of interest were the priority rule (Giveway and Stop), the road section (0-33, 33-66 and 66-100 m), and the expected traffic density (Lower and Higher). Planned contrasts analyses were also conducted. The average values and standard deviations of the dependent variables are presented in Table 3.

\begin{tabular}{lrrrrr} 
& & \multicolumn{2}{c}{ Give-way } & \multicolumn{2}{c}{ Stop } \\
Traffic & Road section & Head & Gaze & Head & Gaze \\
\hline \multirow{3}{*}{ Lower } & $100-66 \mathrm{~m}$ & $3.93(1.35)$ & $7.00(1.62)$ & $4.42(2.01)$ & $5.30(1.57)$ \\
& $66-33 \mathrm{~m}$ & $4.55(2.54)$ & $10.02(2.36)$ & $5.25(1.92)$ & $6.96(1.46)$ \\
& $33-0 \mathrm{~m}$ & $6.46(1.84)$ & $9.38(2.78)$ & $8.05(3.73)$ & $9.74(4.18)$ \\
\hline \multirow{3}{*}{ Higher } & $100-66 \mathrm{~m}$ & $5.74(2.59)$ & $6.82(2.25)$ & $4.06(2.51)$ & $7.14(3.59)$ \\
& $66-33 \mathrm{~m}$ & $4.65(2.15)$ & $5.93(3.58)$ & $4.21(2.38)$ & $8.13(2.96)$ \\
& $33-0 \mathrm{~m}$ & $7.09(3.21)$ & $10.24(2.74)$ & $6.63(2.21)$ & $8.87(2.52)$
\end{tabular}

Table 3: Mean and standard deviation values (in degrees) for the head and gaze horizontal eccentricity, according to the expected traffic density and road section.

Gaze eccentricity. A significant main effect was found for the road section: $F(2,26)=16.13, M S E=7.89, p<.001, \eta^{2}=0.554$. The priority rule, $F(1,13)$ $=2.85, p=0.115$; and the expected traffic density, $F(1,13)<1, p=0.702$, 
were not significant. No significant interaction was observed: priority rule $\times$ road section, $F(2,26)<1, p=0.946$; priority rule $\times$ expected traffic density, $F(1,13)=3.84, p=0.072$; expected traffic density $\times$ road section, $F(2,26)=$ $3.14, p=0.060$. A significant double interaction effect was found between the priority rule, the road section and the expected traffic density, $F(2,26)=12.92$, $M S E=3.30, p<.001, \eta^{2}=0.498$ (see Figure 7).

The planned contrasts analysis did not indicate any significant difference between the Lower and Higher expected traffic densities in the Give-way condition for the 100-66 and 33-0 meters sections (100-66: $p=0.804 ; 33-0: p=0.409)$. In the same Give-way condition, a difference between Lower and Higher traffic density was found for the 66-33 meters road section $(p=0.005)$, with higher 415 eccentricities in the Lower $\left(\mathrm{M}=10.02^{\circ}, \mathrm{SD}=2.36^{\circ}\right)$ than in the Higher condition $\left(\mathrm{M}=5.93^{\circ}, \mathrm{SD}=3.58^{\circ}\right)$. In the Stop condition, no significant difference between the Lower and Higher expected traffic density was found, whatever the section (100-66: $p=0.087 ; 66-33: p=0.173 ; 33-0: p=0.416)$.

Head eccentricity. One significant main effect was observed, for the road section:

420 $F(2,26)=18.24, M S E=6.18, p<.001, \eta^{2}=0.584$. The effect of the priority rule, $F(1,13)<1, p=0.932$, and the expected traffic density, $F(1,13)<1, p$ $=0.878$, were not significant.

No significant interaction was observed: priority rule $\times$ road section, $F(2,26)$ $=1.14, p=0.335$; priority rule $\times$ expected traffic density, $F(1,13)=3.41, p=$ 0.088 ; expected traffic density $\times$ road section, $F(2,26)=1.76, p=0.192$. No double interaction was observed, $F(2,26)<1, p=0.819$.

\subsection{Familiarity}

The analyses were restricted to six out of the seven Give-way conditions (see Table 11. Two $2 \times 3$ repeated measures ANOVAs were conducted respectively on the gaze and head horizontal eccentricity. The factors of interest were the familiarity (First and Second passage) and the road section. The average values and standard deviations are presented in Table 4. 

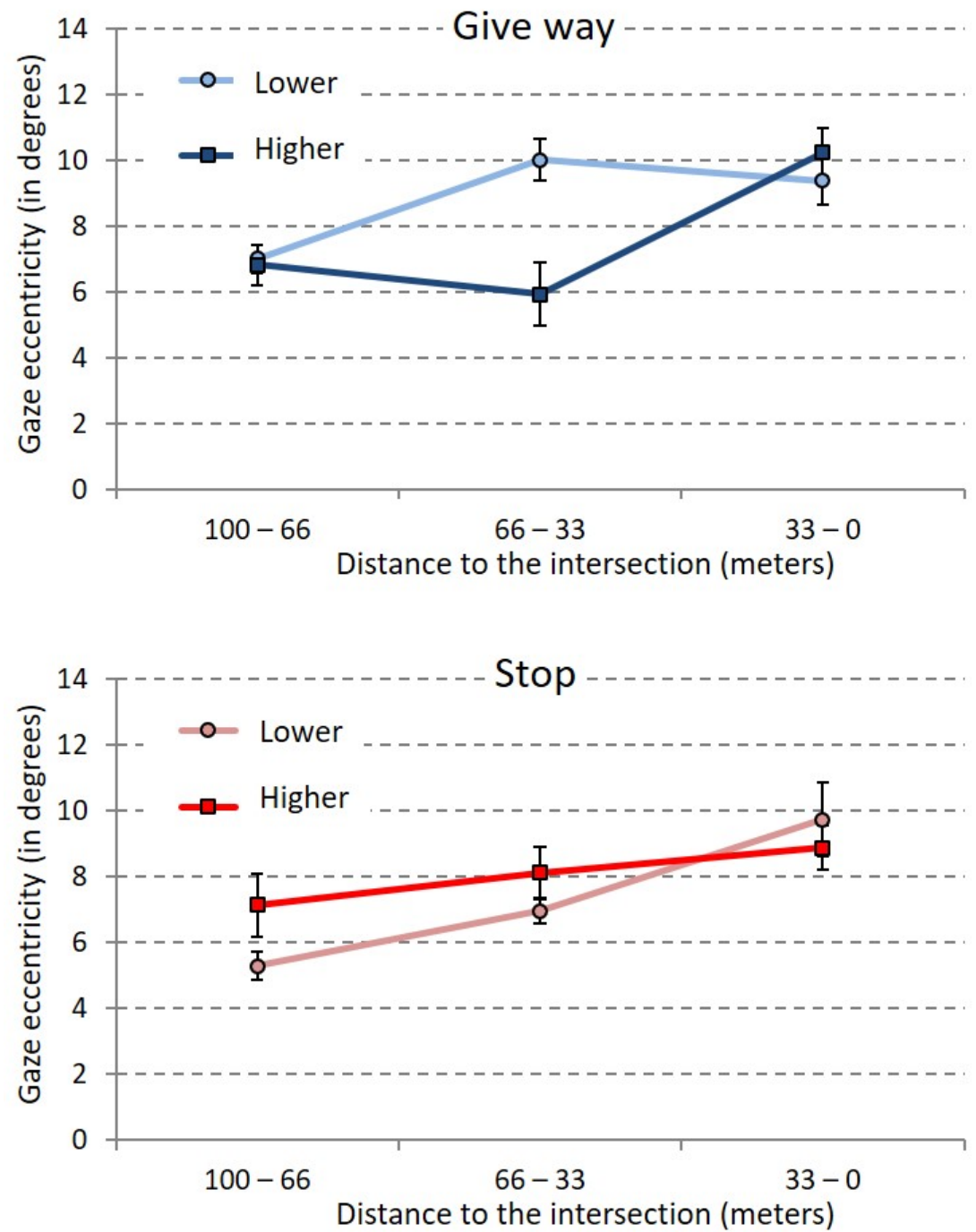

Figure 7: Horizontal eccentricity of the gaze (in degree) in the Give-way and Stop conditions, depending on the road section and of the expected traffic density.

Gaze eccentricity. One significant main effect was observed for the road section: $F(2,26)=7.93, M S E=7.06, p=0.002, \eta^{2}=0.379$. The familiarity was not ${ }_{435}$ significant: $F(2,26)=3.66, p=0.078$. A significant interaction was found, $F(2,26)=15.31, M S E=3.10, p<.001, \eta^{2}=0.541$.

The planned contrast analysis showed no significant difference between the 


\begin{tabular}{crrr} 
Passage & Section & Head & Gaze \\
\hline \multirow{3}{*}{ First } & $100-66 \mathrm{~m}$ & $3.98(1.63)$ & $6.09(2.13)$ \\
& $66-33 \mathrm{~m}$ & $5.36(2.04)$ & $10.80(3.71)$ \\
& $33-0 \mathrm{~m}$ & $6.59(1.95)$ & $9.07(2.95)$ \\
\hline \multirow{3}{*}{ Second } & $100-66 \mathrm{~m}$ & $4.84(1.91)$ & $6.97(1.42)$ \\
& $66-33 \mathrm{~m}$ & $4.24(2.05)$ & $6.83(1.60)$ \\
& $33-0 \mathrm{~m}$ & $7.08(2.03)$ & $9.16(2.44)$
\end{tabular}

Table 4: Mean and standard deviation values (in degrees) for the head and gaze horizontal eccentricity, according to the familiarity and road section.

two passages on the 100-66 and 33-0 meters road sections (100-66: $p=0.215$; 33-0: $p=0.863)$, but a difference was found in the 66-33 meters road section ( $p$ $\left.{ }_{440}=0.002\right)$, with larger horizontal eccentricities during the First $\left(\mathrm{M}=10.80^{\circ}, \mathrm{SD}\right.$ $\left.=3.71^{\circ}\right)$ than during the Second passage $\left(\mathrm{M}=6.83^{\circ}, \mathrm{SD}=1.60^{\circ}\right)$, see Figure 8

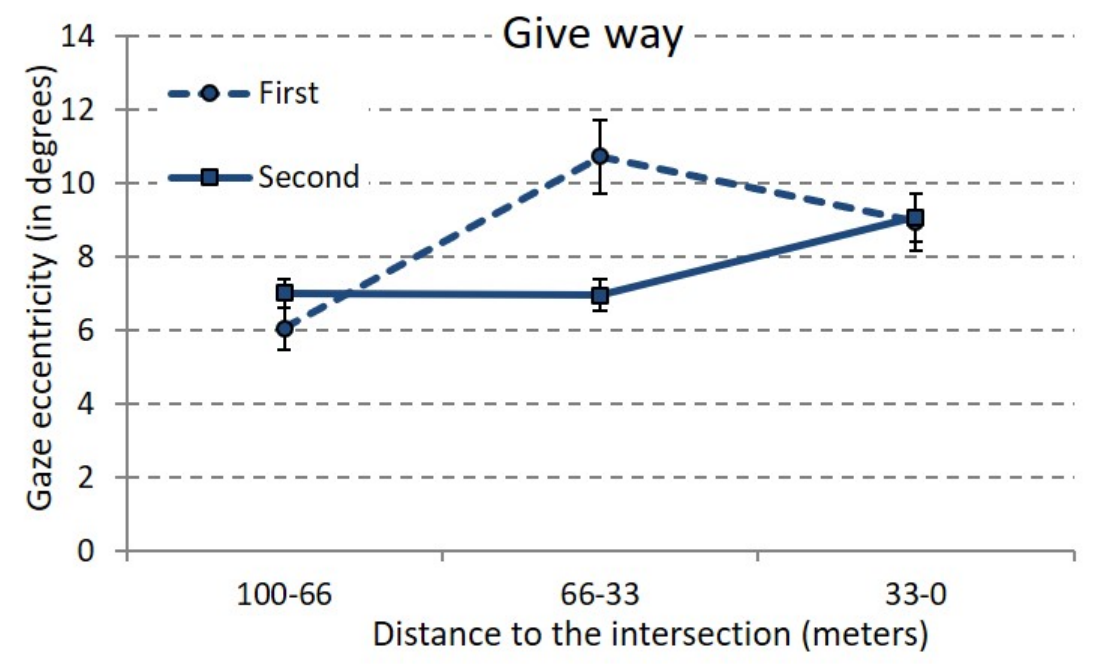

Figure 8: Horizontal eccentricity of the gaze (in degree) in the Give-way conditions according to the road section and the familiarity.

Head eccentricity. There was no main effect of the familiarity on head eccentricity, $F(2,26)<1, p=0.815$, but there was a significant main effect of the road section, $F(2,26)=12.45, M S E=3.80, p<.001, \eta^{2}=0.490$, and a significant ${ }_{445}$ effect of interaction between familiarity and road section, $F(2,26)=3.66, M S E$ 
$=2.12, p=0.040, \eta^{2}=0.220$.

The planned contrast analysis did not indicate any significant difference between the First and Second passages, regardless of the road section (100-66: $p=0.213 ; 66-33: p=0.095 ; 33-0: p=0.109)$.

In order to understand the differences that lead to a significant interaction effect, a post-hoc analysis of multiple comparisons was conducted (Tukey HSD). For the First passage, this analysis did not find any significant difference between the 100-66 and the 66-33 meters road sections $(p=0.160)$, or between the 66 33 and the 33-0 meters road sections $(p=0.259)$, but a difference was found between the 100-66 and the 33-0 meters road sections $(p<.001)$. For the Second passage, no difference was found between the 100-66 and 66-33 meters road sections $(p=0.997)$, but a significant difference was found between the $66-33$ and 33-0 meters road sections $(p<.001)$.

\section{Discussion}

This study investigated the effect of three factors, the priority rule, the expected traffic density and the familiarity, on visual exploration during road intersections approaches. Two indexes of visual exploration have been considered: the gaze and head horizontal eccentricities. The intersection approach was split into three road sections, 100-66 m before the intersection, $66-33 \mathrm{~m}$ and

465 the last $33 \mathrm{~m}$.

The results for each factor of interest will be discussed as follows. First, the main results are discussed. Then, the first two factors of interest, the priority rule and the expected traffic density, are discussed together in reference to previous studies conducted in a driving simulator (Lemonnier et al., 2014, 2015).

470 The familiarity refers more specifically to the work of Martens \& Fox (2007) and is be discussed in this regard.

\subsection{Gaze and head eccentricities.}

The observed effects for the head horizontal eccentricity seem less marked than for the gaze. According to Land \& Tatler (2009), in everyday life, gaze 
changes are made by moving the head and eyes. Up to $30^{\circ}$ changes, one third of the rotation is supported by a head rotation. Beyond $30^{\circ}$, the contribution of the head becomes more important. Below $20^{\circ}$, the movement would be ensured almost exclusively by a change in the gaze position. In our study, the gaze and head angles are on average below $20^{\circ}$ (see Figure 6), which may explain that

480 effects were stronger on the gaze than on the head.

A temporal shift between the gaze and head horizontal eccentricities was observed. Specifically, in the Give-way conditions, the gaze angles begin to increase during the second road section (66-33 meters), while the head angles only increase in the third section (last 33 meters). The following pattern may be

485 speculated: drivers begin to shift their gaze to the left and right to make their decision, and then the head follows for a better muscular comfort. Moreover, the accuracy of spatial perception is lower when the eyes and head are oriented in different directions (Blohm et al., 2008, Burns et al., 2011). Arriving at an intersection, the drivers need to shift their gaze more often from the lateral branches (for decision making) to the road ahead (for vehicle control).

Even though the gaze horizontal eccentricity corresponds better to visual exploration, $\eta^{2}$ was always more important for the head than for the gaze horizontal eccentricity. This implies less variability with the head than with the gaze, which makes the head horizontal eccentricity a more robust measure.

\subsection{The value and the bandwidth of visual information}

Road section. The first factor studied was the road section, i.e. the distance to the intersection, which accounted for the dynamic aspect of driving. We did not have a specific hypothesis about it; it was the interactions with the other factors that was under study. We therefore analyzed this factor in conjunction with other factors.

It can be speculated that the position of the driver relative to the intersection influences the pattern of visual exploration (Lemonnier et al. 2015). As the distance to the intersection decreases and temporal pressure increases, the effects of each of the three previous factors, the priority rule, the expected traffic density 
and the familiarity, are expected to increase.

Priority rule. Concerning the priority rule, similar average gaze and head horizontal eccentricities were found in the three priority rule conditions in the beginning of the intersection approach (100-66 meters): $6^{\circ}$ for the gaze and $5^{\circ}$ for the head. Then, approaching the intersection, these two dependent variables - the gaze and head horizontal eccentricities - seem to increase in the Give-way and Stop conditions, without any difference between these two conditions, whereas they do not change in the Priority condition.

Larger horizontal eccentricities in the Give-way than in the Priority conditions is consistent with our predictions. More visual exploration is needed, because the lateral information value is higher in the Give-way condition.

An interaction was found with the road section factor: there is an increase in gaze eccentricity in the Give-way condition between the first (100-66 meters) and the last road section (last 33 meters) while gaze eccentricity only increases between the second and last section in the Stop condition.

520 In a previous work in a similar situation of intersection approach in a driving simulator (Lemonnier et al. 2014), the presence of a second task of decisionmaking was speculated to come into play once the decision to stop had been taken: deciding when to restart. The gaze horizontal eccentricity during the last section in the Stop condition is consistent with this additional decision-making 525 process, which may explain the increased search for visual information from the lateral branches near the intersection. The decision would therefore not occur during the first (100 - 66 meters) but during the second (66 - 33 meters) section, and would be followed by an anticipation process, as proposed by Lemonnier et al. (2014).

530 Expected traffic density. The expected traffic density is a factor of interest that was built a posteriori. The only differences observed between the two traffic conditions were at Give-way intersections. The gaze horizontal eccentricity was higher with a Lower than with a Higher expected traffic; this stands for the 66-33 meters road section only. 

way intersection. It can be assumed that this decision was more difficult to take when the situation was more ambiguous, that is, when the participant was in a situation where he could have considered passing. With a Lower expected traffic density, the decision to stop was probably more difficult to make. Conversely,

540 when the expected traffic density was Higher, the decision to stop was more obvious.

We have seen that the decision-making task to stop or not at an intersection can be categorized as a tactical task, in the sense of Michon (1985), and that it is performed in parallel with the ongoing operational task of controlling the 545 vehicle. Thus, we can rephrase the absence of any effect in the Higher expected traffic density condition as a disinvestment from the tactical task in favor of the operational task. This explanation is consistent with our observations, where the difference between Lower and Higher traffic appears on the one hand, with a decrease of the gaze horizontal eccentricity in the Higher condition along road sections, which can be interpreted as focusing on the information relevant to the operational task; and on the other hand, with the increase in the gaze horizontal eccentricity in the Lower traffic condition when approaching the intersection, which can be interpreted as an increase of information collection relevant to the decision-making task.

555 In short, at 100-66 meters, the visual exploration appears to be minimal under all three priority rule conditions. At 66-33 meters, it remains close to this baseline in the Priority and Stop conditions, and begins to increase in the Give-way condition with the need to make the decision to stop or not.

The mean horizontal eccentricity is more important with Lower traffic. In the last 33 meters, the need for information from the lateral branches is also due to the anticipation of the next decision, when to restart, as well as in the Stop condition. In the Priority condition, the information on the lateral branches of the intersection only weakly contributes to the decision to stop or not, the value of this information is near the baseline. The expected traffic density only has 565 an influence when it modulates the decision-making, so when the decision is the 
hardest to take, in the Give-way condition 66-33 meters from the intersection.

In a previous driving simulator study (Lemonnier et al., 2014), the decision to stop or not was made on average 60 meters before the intersection (Svenson, 1992 Quétard et al. 2016). This distance seemed to correspond to the time when the information collected was sufficient to make the decision regardless of the priority rule. Indeed, 60 meters is the minimum distance of comfort to stop at an average speed of around $90 \mathrm{~km} / \mathrm{h}$. Our results in this field study are consistent with these previous observations as the Give-way decision occurs during the 66-33 meters road section. It would have been interesting to describe more precisely the driver's positions with respect to the intersection, to estimate if this critical zone is precisely at 60 meters. One of the differences between simulator and real-life experience here is the poor visual environment in the simulator, and more data is needed to understand whether this critical area is determined by the amount of visual information available or by the motor constraints of the task.

\subsection{Familiarity}

The familiarity was only considered in the Give-way conditions. With respect to gaze, higher horizontal eccentricities were found during the First than during the Second passage at 66-33 meters (no difference was found in the other two road sections). Then, it seems that the familiarity increased between the First and the Second passage with a behavioral effect between 66 and 33 meters. It might be less demanding to activate a mental map of the environment than to conduct an active search for information (Martens, 2004). Thus, during the Second passage, we can postulate the activation of such a mental map by the drivers, at least in the most critical road section in terms of decision-making and information gathering.

During the First passage, higher head horizontal eccentricity were found at 33-0 meters than at 100-66 meters. During the Second passage, a difference was found between 66-33 meters and 33-0 meters, but not between 100-66 meters 595 and 66-33 meters. It might be that the active search for visual information 
related to the decision-making task starts later when the driver is even slightly familiar with the environment. Another hypothesis is that the information initially collected during the intersection approach will not be used directly for decision-making, but will provide a first impression of the environment in order to prepare the information gathering for this decision making.

The variability of the gaze horizontal eccentricity was more important during the First $\left(\mathrm{SD}=3.71^{\circ}\right)$ than during the Second $\left(\mathrm{SD}=1.60^{\circ}\right)$ passage. This is consistent with the results from Martens \& Fox (2007), where the standard error also decreases with the number of passages.

Martens \& Fox (2007) have analyzed the fixation duration and the number of fixations in predefined areas containing information (e.g., signs, markings, etc.) to study the learning effect. They found a decrease in the duration and frequency of fixations in these predefined zones with learning. Our results are in agreement with their study, with the difference that we used mean horizontal eccentricity, not regions of interest (ROIs). In addition, the learning effect in our experiment was already present during the Second passage, while in Martens \& Fox (2007), participants conducted three consecutive days in a row. It is therefore important to note: $1 /$ that there is an effect of familiarity as soon as the Second passage, and that this effect is present despite the very important experimental noise and 615 the low number of participants; $2 /$ that it is conceivable to apprehend the level of information need associated with the decision making task, and therefore the difficulty of the task, simply by collecting the gaze horizontal eccentricity, which opens the way to possible applications based on embedded eye tracking systems.

In terms of methodology, the head and gaze horizontal eccentricities are found to be useful behavioral data in real driving situations. They can be easily collected, as more and more vehicles are equipped with oculometric systems, as well as in immersive virtual environments ( $\mathrm{Hu}$ et al., 2019). In addition, they do not require dynamic ROIs to be defined, either a priori or a posteriori. Indeed, ROIs outside the vehicle change continuously during the drive if they are 625 based on semantic cues (e.g. "the road ahead" or the "intersected road"). Most eye tracking systems lack automatic tools allowing defining dynamic ROIs from 
semantic cues. It is interesting to note that such simple dependent variables as the head and gaze horizontal eccentricities are relevant to describe some aspect of the visual exploration in relation to these semantic ROIs. It is then possible

${ }_{630}$ for embedded applications (driver monitoring, ADAS, autonomous vehicles) to extract these data in increments of a few meters, to analyze them, and to propose a "diagnosis of road exploration", almost in real time.

\section{Conclusion}

The model proposed by Wickens et al. (2003) is a very general model of attention allocation in multi-task situations. It has been validated in several experimental situations, mainly in the lab with driving and flight simulators. Our study can be seen as a partial field validation of this general model in a specific situation: the intersection approach. Importantly, the predictions of the model have been validated despite the experimental noise and all the 640 uncontrolled factors that obviously occur in the field. Thus, the effects of the priority rule, the expected traffic density and the familiarity seem particularly robust factors to understand the driver's gaze allocation on the road.

\section{References}

Allen, T. M., Lunenfeld, H., \& Alexander, G. J. (1971). Driver information needs. Highway Research Board, 36, 102-115.

Awh, E., Belopolsky, A. V., \& Theeuwes, J. (2012). Top-down versus bottomup attentional control: A failed theoretical dichotomy. Trends in cognitive sciences, 16, 437-443.

Benjamin, D. J., Berger, J. O., Johannesson, M., Nosek, B. A., Wagenmakers, (2018). Redefine statistical significance. Nature Human Behaviour, 2, 6-10. 
Blohm, G., Khan, A. Z., Ren, L., Schreiber, K. M., \& Crawford, J. D. (2008).

Depth estimation from retinal disparity requires eye and head orientation signals. Journal of vision, 8, 3-3.

${ }_{655}$ Burns, J. K., Nashed, J. Y., \& Blohm, G. (2011). Head roll influences perceived hand position. Journal of vision, 11, 3-3.

Chatziastros, A., Wallis, G. M., \& Bülthoff, H. H. (1999). The effect of field ofview and surface texture on driver steering performance. In A. G. Gale, I. D. Brown, C. M. Haslegrave, \& S. P. Taylor (Eds.), Vision invehicles VII. 660 Amsterdam: Elsevier.

Donges, E. (1978). A two-level model of driver steering behavior. Human Factors: The Journal of the Human Factors and Ergonomics Society, 20, 691-707.

Endsley, M. R. (1995). Toward a theory of situation awareness in dynamic systems. Human Factors, 37, 32-64.

Engström, J., Bärgman, J., Nilsson, D., Seppelt, B., Markkula, G., Piccinini, G. B., \& Victor, T. (2018). Great expectations: a predictive processing account of automobile driving. Theoretical issues in ergonomics science, 19, $156-194$.

670 Foulsham, T., Walker, E., \& Kingstone, A. (2011). The where, what and when of gaze allocation in the lab and the natural environment. Vision Research, $51,1920-1931$.

Hayhoe, M., \& Ballard, D. (2005). Eye movements in natural behavior. Trends in Cognitive Science, 9, 188-194.

675 Hu, Z., Zhang, C., Li, I., Wang, G., \& Manocha, D. (2019). Sgaze: A data-driven eye-head coordination model for realtime gaze prediction. IEEE transactions on visualization and computer graphics, 25, 2002-2010. 
Johnson, V. E. (2013). Revised standards for statistical evidence. Proceedings of the National Academy of Sciences, 110, 19313-19317.

68 Koch, C., \& Ullman, S. (1985). Shifts in selective visual attention: towards the underlying neural circuitry. Human Neurobiology, 4, 219-227.

Kujala, T., Mäkelä, J., Kotilainen, I., \& Tokkonen, T. (2016). The attentional demand of automobile driving revisited: occlusion distance as a function of task-relevant event density in realistic driving scenarios. Human factors, 58 , $685 \quad 163-180$.

Land, M. (2004). Eye movements in daily life. In L. Chalupa, \& J. Werner (Eds.), The visual neurosciences (pp. 1357-1368). Cambridge, MA: MIT.

Land, M., \& Tatler, B. (2009). Driving. In M. Land, \& B. Tatler (Eds.), Looking and acting: vision and eye movements in natural behaviour (pp. 117-141).

690 New York: Oxford University Press.

Land, M. F., \& Furneaux, S. (1997). The knowledge base of the oculomotor system. Philosophical Transactions of the Royal Society of London. Series B: Biological Sciences, 352, 1231-1239.

Land, M. F., \& Horwood, J. (1995). Which parts of the road guide steering? $695 \quad$ Nature, 377, 339-340.

Lappi, O. (2014). Future path and tangent point models in the visual control of locomotion in curve driving. Journal of Vision, 14, 1-21.

Lappi, O., \& Mole, C. (2018). Visuomotor control, eye movements, and steering: A unified approach for incorporating feedback, feedforward, and internal models. Psychological bulletin, 144, 981-1001.

Lappi, O., Rinkkala, P., \& Pekkanen, J. (2017). Systematic observation of an expert driver's gaze strategy - an on-road case study. Frontiers in psychology, 8,620 . 
Lemonnier, S., Brémond, R., \& Baccino, T. (2014). Discriminating cognitive processes with eye movements in a decision-making driving task. Journal of Eye Movement Research, 7, 14p.

Lemonnier, S., Brémond, R., \& Baccino, T. (2015). Gaze behavior when approaching an intersection: Dwell time distribution and comparison with a quantitative prediction. Transportation Research Part F: Traffic Psychology and Behaviour, 35, 60-74.

Logan, G. D. (2002). An instance theory of attention and memory. Psychological review, 109, 376-400.

Martens, M. H. (2004). Stimuli fixation and manual response as a function of expectancies. Human factors, 46, 410-423.

Martens, M. H., \& Fox, M. (2007). Does road familiarity change eye fixations? A comparaison between watching a video and real driving. Transportation Research Part F: Traffic Psychology and Behaviour, 10, 33-47.

Michon, J. (1985). A critical view of driver behavior models. What do we know, what should we do? In L. Evans, \& R. Schwing (Eds.), Human behavior and traffic safety (pp. 485-521). NY: Plenum Press.

Mole, C. D., Kountouriotis, G., Billington, J., \& Wilkie, R. M. (2016). Optic flow speed modulates guidance level control: New insights into two-level steering. Journal of experimental psychology: human perception and performance, 42, $1818-1838$.

725 Montel, M.-C., Nachtergaële, C., Michel, J.-E., Brenac, T., \& Van Elslande, P. (2004). Voies urbaines : représentations et attentes des conducteurs de jour, de nuit et en soirée. Technical Report INRETS N 259.

Mourant, R., \& Rockwell, T. (1970). Mapping eye-movements patterns to the visual scene in driving: an exploratory study. Human Factors, 14, 325-335. 
ONISR (2017). La sécurité routière en France. Bilan de l'année 2017. La documentation Française, Observatoire National Interministeriel de la Securite Routiere, Paris.

Quétard, B., Quinton, J. C., Mermillod, M., Barca, L., Pezzulo, G., Colomb, M., \& Izaute, M. (2016). Differential effects of visual uncertainty and contextual guidance on perceptual decisions: Evidence from eye and mouse tracking in visual search. Journal of vision, 16, 28-28.

Salvucci, D. D., \& Gray, R. (2004). A two-point visual control model of steering. Perception-London, 33, 1233-1248.

Senders, J. W. (1966). A re-analysis of the pilot eye-movement data. IEEE Trans. on Human Factors in Electronics, 7, 103-106.

Senders, J. W., Kristofferson, A., Levison, W., Dietrich, C., Ward, J. et al. (1967). The attentional demand of automobile driving. Highway Research Record, 195, 15-33.

Shinoda, H., Hayhoe, M., \& Shrivastava, A. (2001). What controls attention in natural environments? Vision Research, 41, 3535-3546.

Solt, J. (2017). La navigation urbaine des enfants-piétons : Approche développementale et ergonomique. Ph.D. thesis Université de Lorraine.

Svenson, O. (1992). Differentiation and consolidation theory of human decision making: A frame of reference for the study of pre-and post-decision processes. Acta Psychologica, 80, 143-168.

Tatler, B., Hayhoe, M., Land, M. F., \& Ballard, D. (2011). Eye guidance in natural vision: Reinterpreting salience. Journal of Vision, 11, 1-23.

Trick, L. M., Enns, J. T., Mills, J., \& Vavrik, J. (2004). Paying attention behind the wheel: a framework for studying the role of attention in driving. 
Werneke, J., \& Vollrath, M. (2012). What does the driver look at? the influence of intersection characteristics on attention allocation and driving behavior. Accident Analysis \& Prevention, 45, 610-619.

Wickens, C. D., Goh, J., Helleberg, J., Horrey, W. J., \& Talleur, D. A. (2003). Attentional models of multitask pilot performance using advanced display technology. Human Factors, 45, 360-380.

Wickens, C. D., Helleberg, J., Goh, J., Xu, X., \& Horrey, W. J. (2001). Pilot Task Management: Testing an Attentional Expected Value Model of Visual Scanning. Technical Report Aviation Research Lab.

765 Wolfe, J. M., \& Horowitz, T. S. (2004). What attributes guide the deployment of visual attention and how do they do it? Nature Reviews Neuroscience, 5, $1-7$. 